\title{
Rupturing cancer cells by the expansion of functionalized stimuli-responsive hydrogels
}

\begin{abstract}
Yan Fang ${ }^{1,3}$, Jiajun $\operatorname{Tan}^{2,3}$, Sierin $\operatorname{Lim}^{2}$ and Siowling Soh ${ }^{1}$
Using particles with different functionalities for treating cancer has many advantages over other methods (for example, better access to remote parts of the body); however, current chemical (for example, chemotherapy) and biological (for example, immunotherapy) methods still face many challenges. Here, we describe a fundamentally different approach: using the physical force of an expanding stimuli-responsive hydrogel to rupture cancer cells attached on its surface. Specifically, we coated temperature-responsive hydrogels with a layer of cell-adherent arginine-glycine-aspartate (RGD) peptides. The approach involved first allowing cancer cells to attach onto the surface of the hydrogels, and then applying a change in temperature. As the hydrogel underwent a chemical transformation and expanded due to the stimulus, the cancer cells attached to it ruptured. The results from staining the cells with trypan blue, observing them using SEM, and analyzing them using the MTT assay showed that both breast and lung cancer cells died after the hydrogel expanded; hence, we showed that this physical force from the expanding hydrogel is strong enough to rupture the cancer cells. In addition, the force derived from the expanding hydrogel was determined separately to be larger than that needed to rupture typical cells. This physical approach is conceptually simple, technically easy to implement, and potentially generalizable for rupturing a wide range of cells.
\end{abstract}

NPG Asia Materials (2018) 10, e465; doi:10.1038/am.2017.232; published online 2 February 2018

\section{INTRODUCTION}

Cancer is one of the deadliest diseases in the world and results in millions of deaths per year. ${ }^{1}$ Due to its complex nature, many types of cancer currently remain incurable. To overcome the different types of challenges related to the treatment of cancer, a wide range of methods (for example, surgery and radiotherapy) have been introduced. In particular, the use of particles with different functionalities can address some of these challenges, and is a common method for treatment. One example is the metastasis of cancer: while surgery is incapable of removing cells that have spread, particles can be directed at sites that are not accessible to surgery. ${ }^{2-4}$ In addition, the use of particles is advantageous over other methods of treatment of cancer in many ways. For example, by administering them orally or by injection, the method is minimally invasive to the human body. These routes of administration are relatively simple to implement and do not require the use of sophisticated equipment (for example, linear accelerators) or highly skilled personnel (for example, surgeons); thus, they can be made widely available to the public. Particles are versatile and can be fabricated in different ways (for example, functionalization with different types of molecules on the surface) for treatment.

However, while the use of particles has been successful in some cases, it has its own set of challenges. When particles are used for delivering molecules (for example, chemotherapy), the molecules are not always effective in performing their intended purposes. In addition, some molecules (for example, drugs) may lose their therapeutic efficacy over time as patients develop resistance. When released, molecules tend to diffuse isotropically outward and affect the surrounding healthy cells. In addition to serving as carriers of molecules, other methods that use particles to treat cancer include photothermal therapy and photodynamic therapy. These methods, however, also have their disadvantages, such as limited light penetration and phototoxic response. ${ }^{7-9}$ There is thus a need to develop methods that use particles for killing cancer cells effectively.

Here, we propose a fundamentally different approach of using particles for killing cancer cells: by utilizing the physical force derived from the expansion of stimuli-responsive hydrogels to rupture the cells. Stimuli-responsive hydrogels are a class of materials that undergo a chemical transformation-and subsequent expansion or contraction - under the influence of a specific external stimulus. These hydrogels have been studied for many decades and can be fabricated to respond to a wide range of stimuli, including $\mathrm{pH}$, temperature, pressure, electric field, gases, salts, alcohol, glucose and many types of biomolecules (for example, enzymes and antigens). ${ }^{10,11}$ On the surface of the stimuli-responsive hydrogel, we coat a layer of cell-adherent molecules. Hence, the basic principle of our approach involves two

${ }^{1}$ Department of Chemical and Biomolecular Engineering, National University of Singapore, Singapore, Singapore and ${ }^{2}$ School of Chemical and Biomedical Engineering, Nanyang Technological University, Singapore, Singapore

${ }^{3}$ These authors contributed equally to this work.

Correspondence: Professor S Soh, Department of Chemical and Biomolecular Engineering, Faculty of Engineering, National University of Singapore, Block E5, \#02-15, 4 Engineering Drive 4, Singapore 117585, Singapore.

E-mail: chessl@nus.edu.sg

Received 27 June 2017; revised 1 October 2017; accepted 9 November 2017 


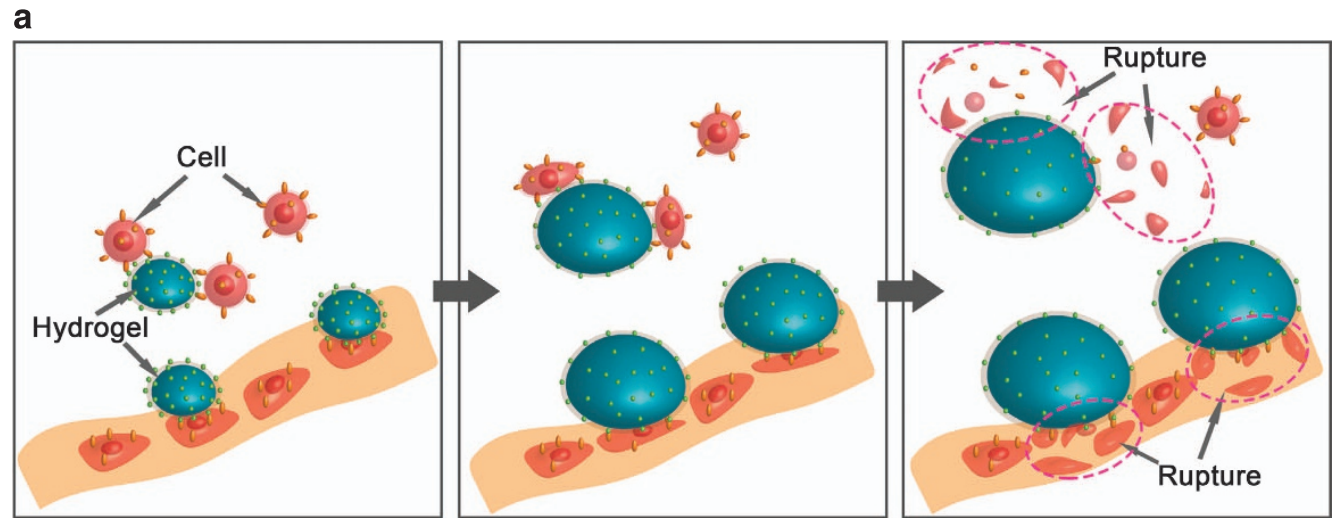

b
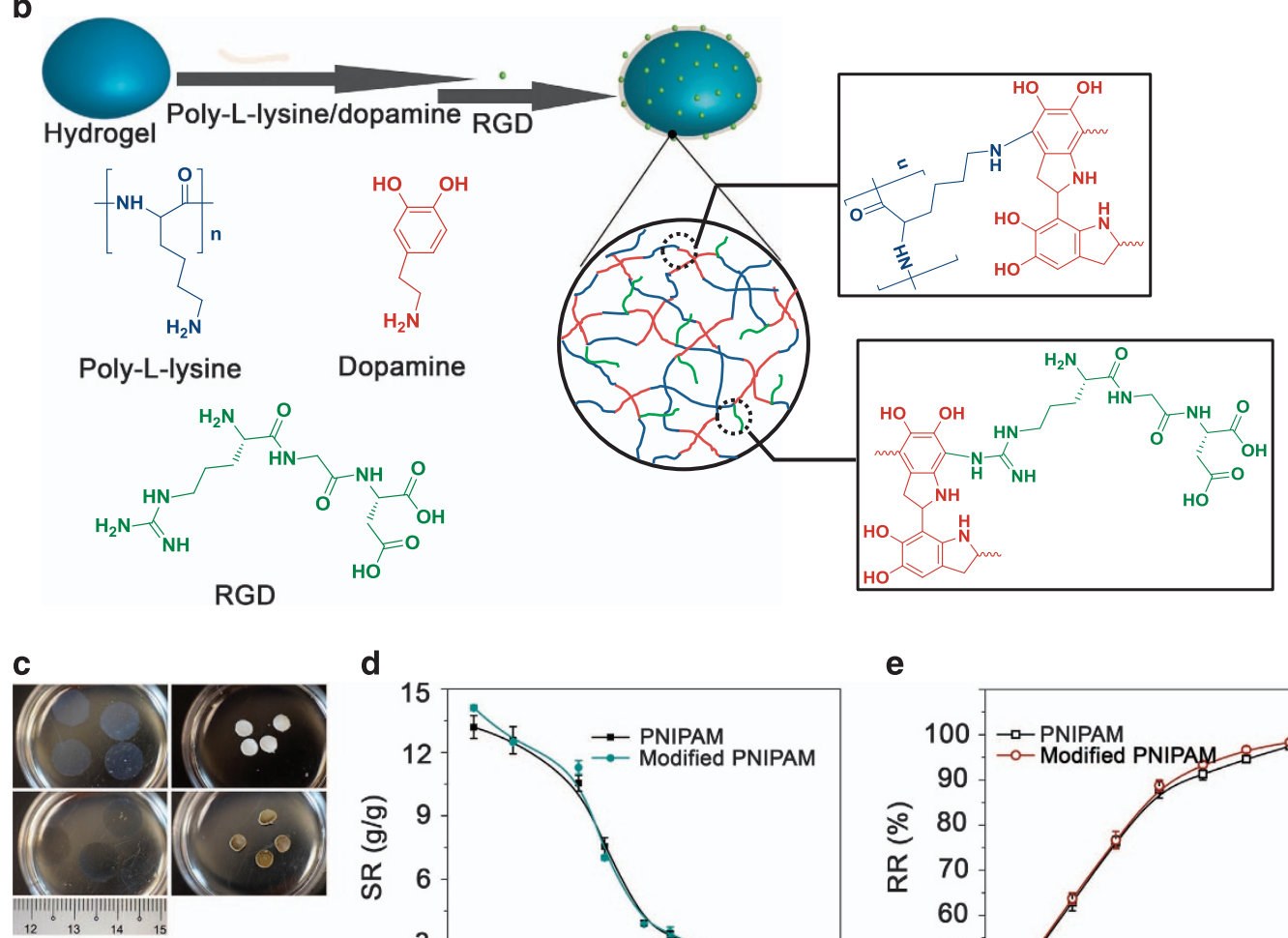

d

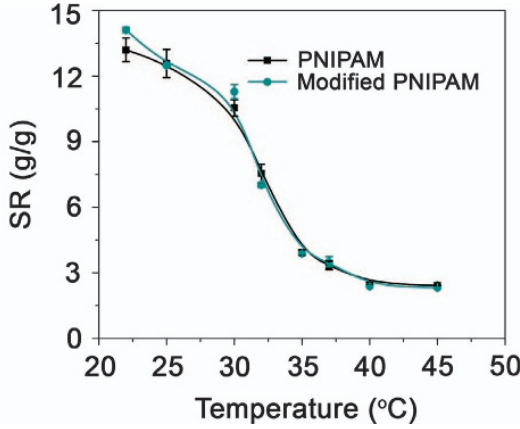

$\mathbf{e}$

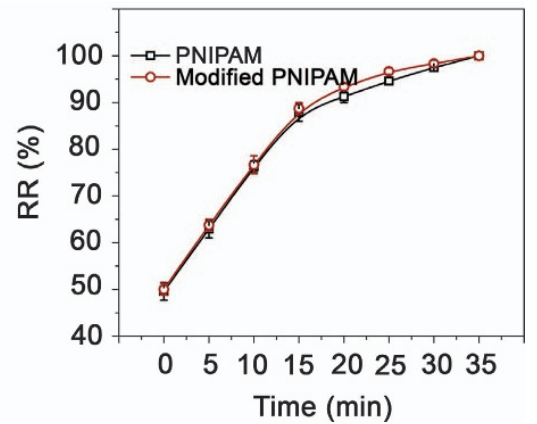

Figure 1 Rupturing cancer cells using the physical force of expanding stimuli-responsive hydrogels. (a) Scheme illustrating the process in which the cancer cells first attach onto the surfaces of the stimuli-responsive hydrogels. After the hydrogels expand under the influence of an external stimulus (for example, temperature), the cancer cells rupture. (b) Scheme illustrating the surface modification of the hydrogel. The surface was coated first with a layer of polydopamine (PDA) and poly-L-lysine (PLL) and then with a layer of RGD peptides for attaching the cancer cells. (c) Photographs of the temperatureresponsive hydrogels (PNIPAM) with or without surface modification at different temperatures. Nascent hydrogels incubated at $22{ }^{\circ} \mathrm{C}$ (top left), and at $37^{\circ} \mathrm{C}$ (top right); RGD-modified hydrogels incubated at $22^{\circ} \mathrm{C}$ (bottom left) and at $37{ }^{\circ} \mathrm{C}$ (bottom right). (d) Comparison of the swelling ratio (SR) and (e) the recovery ratio $(R R)$ of the temperature-responsive hydrogels with and without surface modification.

steps (Figure 1a). First, when the stimuli-responsive hydrogel comes into contact with the cancer cells, the cells attach onto the surface of the hydrogel. After attachment, we expand the hydrogel by introducing an external stimulus. The introduction of an external stimulus, such as a change in temperature (for example, therapeutic hypothermia or hyperthermia therapy) or the use of an electric field, is compatible with several existing treatments of cancer (Supplementary Information, Section 1). ${ }^{12-14}$ Subsequently, the physical force that originates from the expansion ruptures the cancer cell. Conceptually, one of the most important fundamental requirements of this approach is that the force produced by the expanding stimuli-responsive hydrogel is large enough to rupture cells attached onto its surface. Therefore, the main objective of this preliminary work is to show experimentally that this physical force is sufficiently large to kill cancer cells (that is, the necessary first step before further development of the technology). 


\section{MATERIALS AND METHODS}

\section{Materials}

$N$-Isopropylacrylamide (NIPAM), $N, N^{\prime}$-methylenebisacrylamide (BIS), ammonium persulfate (APS), potassium persulfate (KPS), $N, N, N^{\prime}, N^{\prime}$-tetramethylethylenediamine (TEMED), dopamine hydrochloride, poly-L-lysine solution (PLL, $0.1 \%(\mathrm{w} / \mathrm{v})$ in $\mathrm{H}_{2} \mathrm{O}$ ), poly(ethylene glycol) diacrylate (PEGDA, $\left.M_{\mathrm{n}}=575\right)$, poly (ethylene glycol) methacrylate (PEGMA, $M_{\mathrm{n}}=500$ ), Arg-Gly-Asp (RGD), tris (hydroxymethyl)aminomethane (Tris), Triton-X-100 and trypan blue $(0.4 \%$, liquid, sterile-filtered) were purchased from Sigma-Aldrich (Singapore). Anhydrous magnesium sulfate $\left(\mathrm{MgSO}_{4}\right)$ was purchased from TCI Co., Ltd (Singapore). MDA-MB 231 (ATCC HTB-26) and H358 (ATCC CRL-5807) cells were purchased from American Type Culture Collection. Dulbecco's modified eagle medium and Roswell Park memorial institute (RPMI) 1640 were purchased from Thermo Fisher Scientific (Singapore). Dulbecco's phosphate buffered saline (DPBS), fetal bovine serum and penicillinstreptomycin were purchased from HyClone (Singapore). TrypsinEthylenediaminetetraacetic acid (EDTA) $(0.25 \%)$ was purchased from Gibco (Singapore). All chemicals were used as received. The 24-well plates used were Nunc cell-culture-treated multidishes purchased from Thermo Fisher Scientific (Singapore). Cell culture flasks $\left(75 \mathrm{~cm}^{2}\right)$ were purchased from BD Falcon (Singapore). Tris- $\mathrm{HCl}$ buffer $(\mathrm{pH}=8.5,50 \mathrm{~mm})$ was used for surface modification of hydrogels with PLL and poly(dopamine) (PDA). Phosphate-buffered saline (PBS) $(\mathrm{pH}=7.4,10 \mathrm{~mm})$ was used for immobilizing RGD peptides onto the surface of the hydrogels. DPBS $(\mathrm{pH}=7.4)$ was used for cell culture experiments. The water used in all experiments was deionized and ultra-filtered to $18 \mathrm{M} \Omega \cdot \mathrm{cm}$ using a Millipore Milli-Q gradient system.

\section{Fabrication of the macroscopic temperature-responsive hydrogel}

Poly( $N$-isopropylacrylamide) (PNIPAM) hydrogels were synthesized by first preparing (at $22{ }^{\circ} \mathrm{C}$ ) a $1.5 \mathrm{ml}$ aqueous solution that consisted of $0.10 \mathrm{~g}$ of NIPAM and $0.0050 \mathrm{~g}$ of BIS. We then added $50 \mu \mathrm{l}$ of APS (5\% w/v) and $30 \mu \mathrm{l}$ of TEMED into the solution. The suspension was vigorously mixed with a vortex mixer for $10 \mathrm{~s}$ and then poured into a poly(styrene) (PS) Petri dish for $20 \mathrm{~min}$ at $22^{\circ} \mathrm{C}$. After fabricating the hydrogels, they were washed with ultra-pure water and then freeze-dried $\left(-80^{\circ} \mathrm{C}, 0.25 \mathrm{mbar}\right)$ for $4 \mathrm{~h}$.

\section{Surface modification of PNIPAM hydrogels}

The coating of the PNIPAM hydrogels with dopamine and PLL followed by another coating of the RGD peptides was performed as follows. First, we prepared a solution for coating the hydrogels by dissolving dopamine hydrochloride and PLL in a Tris- $\mathrm{HCl}$ buffer solution $(\mathrm{pH}=8.5,50 \mathrm{~mm})$ with a mass ratio of 1:1 (or a concentration of $2 \mathrm{mg} \mathrm{ml}^{-1}$ for each component in the solution). After presoaking the PNIPAM hydrogels in water for $1 \mathrm{~h}$, they were immersed in the solution for coating. The samples were gently shaken for $1 \mathrm{~h}$ at $22^{\circ} \mathrm{C}$. We then added RGD in $\mathrm{PBS}(\mathrm{pH}=8.5,50 \mathrm{~mm})$ directly into the solution; the final concentrations were $1 \mathrm{mg} \mathrm{ml}^{-1}$ dopamine and PLL and $250 \mu \mathrm{g} \mathrm{ml}^{-1}$ RGD. The reaction was allowed to proceed for another $1 \mathrm{~h}$ at $22^{\circ} \mathrm{C}$. The RGDmodified samples were taken out of the solution, washed three times with PBS, washed three times with water, and then stored in water at $4{ }^{\circ} \mathrm{C}$ before use.

\section{Fabrication of the microscopic gel particles}

Microscopic PNIPAM gel particles (diameter $\sim 15 \mu \mathrm{m}$ ) were prepared by first vigorously mixing a deoxygenated aqueous solution $(25 \mathrm{ml})$ of NIPAM $(0.5 \mathrm{ml}$, $20 \% \mathrm{w}: \mathrm{w}$ ), BIS (the cross-linker; $0.75 \mathrm{ml}, 20 \% \mathrm{w}: \mathrm{w}$ ), and $\mathrm{MgSO}_{4}(10 \mathrm{~g})$ for 1 min with a vortex mixer under a nitrogen atmosphere. The resulting emulsion was allowed to stabilize for $15 \mathrm{~min}$. Subsequently, KPS $(0.9 \mathrm{ml}$, $5 \%$ w:w $)$ and TEMED $(0.5 \mathrm{ml}, 20 \% \mathrm{w}: \mathrm{w})$ were added. The mixture was vigorously mixed for $1 \mathrm{~min}$ and then incubated without stirring for $45 \mathrm{~min}$ at $25^{\circ} \mathrm{C}$. The microscopic gel particles were collected by centrifugation at $2100 \mathrm{~g}$ for $10 \mathrm{~min}$. They were then rinsed with water twice and redispersed in water. Images of the microscopic gel particles were taken by a microscope and an scanning electron microscope (SEM) (FE-SEM, JEOL JSM-6700F). The average diameter of the microscopic gel particles was determined after analyzing the images using ImageJ. Particle size distributions were determined by dynamic light scattering (DLS; Ls 13 320, Beckman Coulter (Singapore)).
We also fabricated microscopic gel particles that were not responsive to temperature. These poly(ethylene glycol) (PEG) gel particles were prepared by the same method as described above for the PNIPAM gel particles, except that the monomer (that is, NIPAM) and the cross-linker (that is, BIS) were replaced with PEGMA and PEGDA, respectively.

\section{Performance of the surface-modified temperature-responsive hydrogel}

After coating the surface of the temperature-responsive hydrogel with PDA and PLL and then with arginine-glycine-aspartate (RGD) peptides, we compared its performance with the original hydrogel that was not coated with these molecules.

First, we compared the amount of swelling of the hydrogels with or without surface modification. In this experiment, we placed the hydrogels (diameter of $4.0 \mathrm{~mm}$ and height of $300 \mu \mathrm{m}$ ) either with or without surface modification into a Petri dish filled with ultra-pure water and incubated them at different temperatures in the range of $22-37^{\circ} \mathrm{C}$ for $24 \mathrm{~h}$. After that, we took the hydrogels out of the solution, removed the excess water on their surfaces with a piece of moistened filter and weighed them. For the dry weight, we prepared another piece of hydrogel, dried it under vacuum at $60^{\circ} \mathrm{C}$ overnight and weighed it. We defined the swelling ratio, $S R$, of the hydrogels as follows:

$$
S R=\frac{W_{\mathrm{s}}-W_{\mathrm{d}}}{W_{\mathrm{d}}}
$$

where $W_{\mathrm{s}}$ is the weight of the hydrogel immersed in water at different temperatures and $W_{\mathrm{d}}$ is the weight of the dry hydrogel.

We also compared the rate of swelling of the temperature-responsive hydrogel with and without surface modification when the temperature was decreased. Experimentally, we first expanded the hydrogels in water at $22^{\circ} \mathrm{C}$ and then contracted them in warm water at $37^{\circ} \mathrm{C}$ for $1 \mathrm{~h}$. The hydrogels were then immersed back in water at $22^{\circ} \mathrm{C}$; the diameter of the hydrogels was measured at $5 \mathrm{~min}$ intervals. We defined the recovery ratio, $R R$, as follows:

$$
R R=\frac{D_{t}}{D_{0}} \times 100
$$

where $D_{t}$ is the diameter of the hydrogel at time $t$ after immersing it in water at $22^{\circ} \mathrm{C}$ and $D_{0}$ is the diameter of the fully swollen hydrogel at $22^{\circ} \mathrm{C}$ and $t=35 \mathrm{~min}$.

\section{Cell seeding and static culture on the hydrogels}

MDA-MB-231 cells and H358 cells were recovered from liquid $\mathrm{N}_{2}$ and cultured in $75 \mathrm{~cm}^{2}$ cell culture flasks. The solution used consisted of Dulbecco's modified eagle medium supplemented with $10 \%$ fetal bovine serum and $1 \%$ penicillin-streptomycin as the growth medium for the MDA-MB-231 cells and RPMI 1640 supplemented with $10 \%$ fetal bovine serum and $1 \%$ penicillinstreptomycin as the growth medium for the H358 cells. Passaging was done at $80 \%$ confluence by washing with DPBS, and the cells were detached using $0.25 \%$ trypsin at $37^{\circ} \mathrm{C}$ for $5 \mathrm{~min}$.

DPBS $(500 \mu \mathrm{l})$ was aliquoted into each well of a 24 -well plate before individual hydrogels were placed into each well. For comparison, we used two types of temperature-responsive hydrogels: the hydrogels that were not coated and the hydrogels that were coated with RGD peptides. The hydrogels were sterilized by placing the 24-well plate under ultraviolet (UV) irradiation for $30 \mathrm{~min}$. The hydrogels were then shrunk by incubating them at $37^{\circ} \mathrm{C}$ for $35 \mathrm{~min}$. The detached cells were first counted using a hemocytometer before centrifuging at $500 \mathrm{~g}$ for $5 \mathrm{~min}$ and then resuspending them in their corresponding growth medium at $1 \times 10^{6}$ cells per $\mathrm{ml}$. The DPBS in each well was extracted with a pipette and replaced with $400 \mu$ l of growth medium preheated at $37^{\circ} \mathrm{C}$. Cells $(100 \mu \mathrm{l})$ were then carefully pipetted onto the shrunken hydrogels to yield a final concentration of $1 \times 10^{5}$ cells suspended in $500 \mu \mathrm{l}$ of growth medium. The seeded cells were kept undisturbed for $48 \mathrm{~h}$ in a $\mathrm{CO}_{2}$ incubator $\left(5 \% \mathrm{CO}_{2}\right)$ at $37^{\circ} \mathrm{C}$ before the hydrogels were expanded. For the control experiments, 24-well plates without any hydrogels were used. The concentration was $1 \times 10^{5}$ cells in $500 \mu$ of growth medium per well. 


\section{Monitoring cell morphology and cell stain}

Cells on the temperature-responsive hydrogels were observed using a microscope (Leica, DFC 300 FX, Wetzlar, Germany) after culturing them for $48 \mathrm{~h}$ at $37^{\circ} \mathrm{C}$. The hydrogels were then expanded at $22^{\circ} \mathrm{C}$ for $35 \mathrm{~min}$, and the morphologies of the cells were observed during the process at $5 \mathrm{~min}$ intervals.

To determine cell death, trypan blue was used to stain the cells. For the two cases in which the macroscopic hydrogels and microscopic gel particles were used, the hydrogels were first allowed to expand at $22{ }^{\circ} \mathrm{C}$ for $35 \mathrm{~min}$. We then added 10 times diluted trypan blue solution into the wells. After $3 \mathrm{~min}$, we washed the wells with DPBS three times. The result was examined by a microscope

\section{Methylthiazolyldiphenyl-tetrazolium bromide (MTT) assay}

Cells were first cultured with and without the hydrogels in 24-well plates for $48 \mathrm{~h}$ at $37^{\circ} \mathrm{C}$ at a concentration of $1 \times 10^{5}$ cells in $500 \mu$ lof growth medium per well. For the plates that contained the hydrogels, the hydrogels were expanded at $22{ }^{\circ} \mathrm{C}$ for $35 \mathrm{~min}$. For a direct comparison, the plates that did not contain the hydrogels were also kept at $22{ }^{\circ} \mathrm{C}$ for $35 \mathrm{~min}$. After that, the cellular culture medium was aspirated and replaced with $500 \mu \mathrm{l}$ of fresh culture medium. We then added $50 \mu \mathrm{l}$ of $5 \mathrm{mg} \mathrm{ml}^{-1}$ MTT in PBS to each well; the final concentration of MTT was $0.5 \mathrm{mg} \mathrm{ml}^{-1}$. The cells were then incubated at $37^{\circ} \mathrm{C}$ for $4 \mathrm{~h}$. Thereafter, the purple formazan crystals were dissolved by adding $550 \mu \mathrm{l}$ per well of solubilizing solution $(10 \%(\mathrm{w} / \mathrm{v})$ sodium dodecyl sulfate supplemented with $0.01 \mathrm{~m}$ hydrochloric acid $(\mathrm{HCl})$ ) into the wells. After incubating the mixture overnight at $37^{\circ} \mathrm{C}, 1 \mathrm{ml}$ of solubilized formazan was aspirated into fresh 24 -well plates, and the results were analyzed by a Wallac 1420 multilabel counter operated at $570 \mathrm{~nm}$. We also performed a control experiment in which we carried out the same procedure except that the hydrogels were not expanded at $22^{\circ} \mathrm{C}$ for $35 \mathrm{~min}$; that is, they remained contracted at $37^{\circ} \mathrm{C}$. Hence, we performed three types of experiments: the experiments in which (i) no hydrogel, (ii) a contracted hydrogel and (iii) an expanded hydrogel were used. All of these three experiments were conducted in triplicate. As a control sample for the MTT measurement, we simply used the cell culture medium (that is, without the addition of cells) and treated it similarly with MTT and the solubilizing solution.

To determine the number of dead cells, we translated the number of live cells obtained from the MTT assay into the number of dead cells as follows. First, we determined the number of live cells for the case when there was no hydrogel, $L_{O}$, from the MTT assay. After conducting the MTT assay three times, we calculated the average number of live cells for the case when there was no hydrogel, $\bar{L}_{O}$. Similarly, we also determined the average number of live cells for the case when the hydrogel was contracted, $\bar{L}_{C}$, and when the hydrogel was expanded, $\bar{L}_{E}$. The number of dead cells were estimated according to Equations (1) and (2).

$$
\begin{aligned}
& N_{\mathrm{C}}=\bar{L}_{O}-\bar{L}_{\mathrm{C}} \\
& N_{\mathrm{E}}=\bar{L}_{O}-\bar{L}_{\mathrm{E}}
\end{aligned}
$$

where $N_{\mathrm{C}}$ and $N_{\mathrm{E}}$ represent the number of dead cells for the cases when the hydrogel was contracted and when the hydrogel was expanded, respectively.

The diameter of the bottom of each well was $15.6 \mathrm{~mm}$, whereas the diameter of the cylindrical temperature-responsive hydrogel was $4 \mathrm{~mm}$. Since the surface area of the temperature-responsive hydrogel was smaller than the area of the bottom of the well, we did not expect the hydrogel to rupture all the cells attached at the bottom of the well. A method to compare the expected number of dead cells, $N_{\mathrm{A}}$, resulting from the expanding hydrogel is to calculate the fraction of the surface area of the hydrogel over the area of the bottom of the well, and multiply that with the average number of live cells.

$$
N_{\mathrm{A}}=\frac{A_{\text {hydrogel }}}{A_{\text {well }}} \times \bar{L}_{O}
$$

where $A_{\text {hydrogel }}$ and $A_{\text {well }}$ represent the surface area of the hydrogel $\left(12.6 \mathrm{~mm}^{2}\right)$ and the bottom of the well $\left(191 \mathrm{~mm}^{2}\right)$, respectively.

\section{Monitoring cell morphology by SEM}

The two types of samples were also analyzed by field-emission scanning electron microscopy (FE-SEM, JEOL JSM-6700F, $5 \mathrm{kV}$ ): cells attached onto the surface of the fully contracted hydrogel at $37^{\circ} \mathrm{C}$ and cells attached onto the surface of the hydrogel after it fully expanded at room temperature. These samples were freeze-dried $\left(-80^{\circ} \mathrm{C}, 0.25 \mathrm{mbar}, 4 \mathrm{~h}\right)$ before analysis.

\section{Measuring the force produced by the expanding hydrogel}

Pieces of double-sided tape (STAR) were cut into dimensions of $4 \mathrm{~mm}$ in length and $1 \mathrm{~mm}$ in width. To increase the strength of the tape, five layers of the tape were stuck on top of each other. They were then attached onto the surface of the contracted hydrogel (cylindrical; $4 \mathrm{~mm}$ in diameter and $300 \mu \mathrm{m}$ in height) using a water acrylic adhesive on both ends of the tape $\left(1 \mathrm{~mm}^{2}\right.$ each). Subsequently, we allowed the contracted hydrogel to gradually expand by placing it in deionized water at $22^{\circ} \mathrm{C}$. We found that the maximum number of tapes that we could adhere onto the hydrogel was five layers; with more layers, the hydrogels bent under the stress of the tape while expanding. We took images of the hydrogel at $3 \mathrm{~min}$ intervals while it expanded. Based on these images, we measured the elongation of the attached tape during the initial expansion $(6 \mathrm{~min})$ of the hydrogel by Photoshop software. The hydrogel started to bend from $9 \mathrm{~min}$ and beyond; hence, we chose to measure the elongation of the tape at $6 \mathrm{~min}$. The expanded length of the tape at $6 \mathrm{~min}$ was $0.25 \mathrm{~mm}$.

In a separate step, we determined the force required to elongate the five layers of tape to a length of $0.25 \mathrm{~mm}$. Specifically, we hung the five layers of double-sided tape stuck together vertically and attached the bottom of the tape to a container. In the container, we added a certain number of small loads (that is, acrylonitrile butadiene styrene plastic resin) until the length elongated to $0.25 \mathrm{~mm}$. The elongation was determined by measuring the length under a microscope. After measuring the mass of the total load (that is, the mass of all the small plastic boxes in the container, the container and the copper wire that was used to attach the tape to the container), we determined that the force exerted on the tape was $1.5 \mathrm{~N}$.

This force produced by the expanding hydrogel was based on adhering the five layers of tape with a total adhesive area of $2 \mathrm{~mm}^{2}$ (that is, $1 \mathrm{~mm}^{2}$ on each end of the tape). For a cell with a much smaller surface area, however, the amount of force that the hydrogel can exert is expected to be much smaller. Cells spread and attach onto a substrate via large molecular assemblies called focal adhesion. The total area of focal adhesion in a typical cell can be estimated to be on the order of $\sim 100 \mu \mathrm{m}^{2}$, as reported in previous studies. ${ }^{15-17}$ For an area of $100 \mu \mathrm{m}^{2}$, the force of $1.5 \mathrm{~N}$ on an area of $2 \mathrm{~mm}^{2}$ is calculated proportionally to be on the order of $\sim 80 \mu \mathrm{N}$ for a single cell. This amount of force acting on a cell is much larger than that needed to rupture cells reported in previous studies.

\section{RESULTS AND DISCUSSION}

\section{Fabrication and characterization of the stimuli-responsive hydrogels coated with RGD}

For coating the surface of the stimuli-responsive hydrogels with a layer of cell-adherent molecules, we used the arginine-glycine-aspartate (RGD) peptides. It is widely reported in the literature that cells can attach onto surfaces coated with these molecules. ${ }^{18-20}$ Experimentally, the RGD peptides can be conjugated onto surfaces via several methods; examples include non-covalent immobilization through hydrophobic interaction, ${ }^{21}$ biotin-streptavidin interactions, ${ }^{22}$ van der Waals interaction, ${ }^{23,24}$ covalent immobilization through self-assembled monolayers ${ }^{25}$ and surface-initiated atom transfer radical polymerization. ${ }^{26}$ However, these methods can be technically complicated, can involve multi-step procedures with long reaction times and/or can immobilize only limited amounts of peptides on the substrates stably. ${ }^{27}$ Recently, a one-step dopamine-assisted deposition of molecules has been introduced as a simple way to prepare functional surfaces. ${ }^{28}$ Polymers deposited using this method include dextran, poly(sulfobetaine methacrylate) and several nonionic polymers. ${ }^{29-31}$ These depositions, however, have poor chemical stability and poor resistance to acidic solvents because the polymers are not covalently bonded to the PDA. Alternatively, a method has been developed to copolymerize dopamine with polyethyleneimine, 

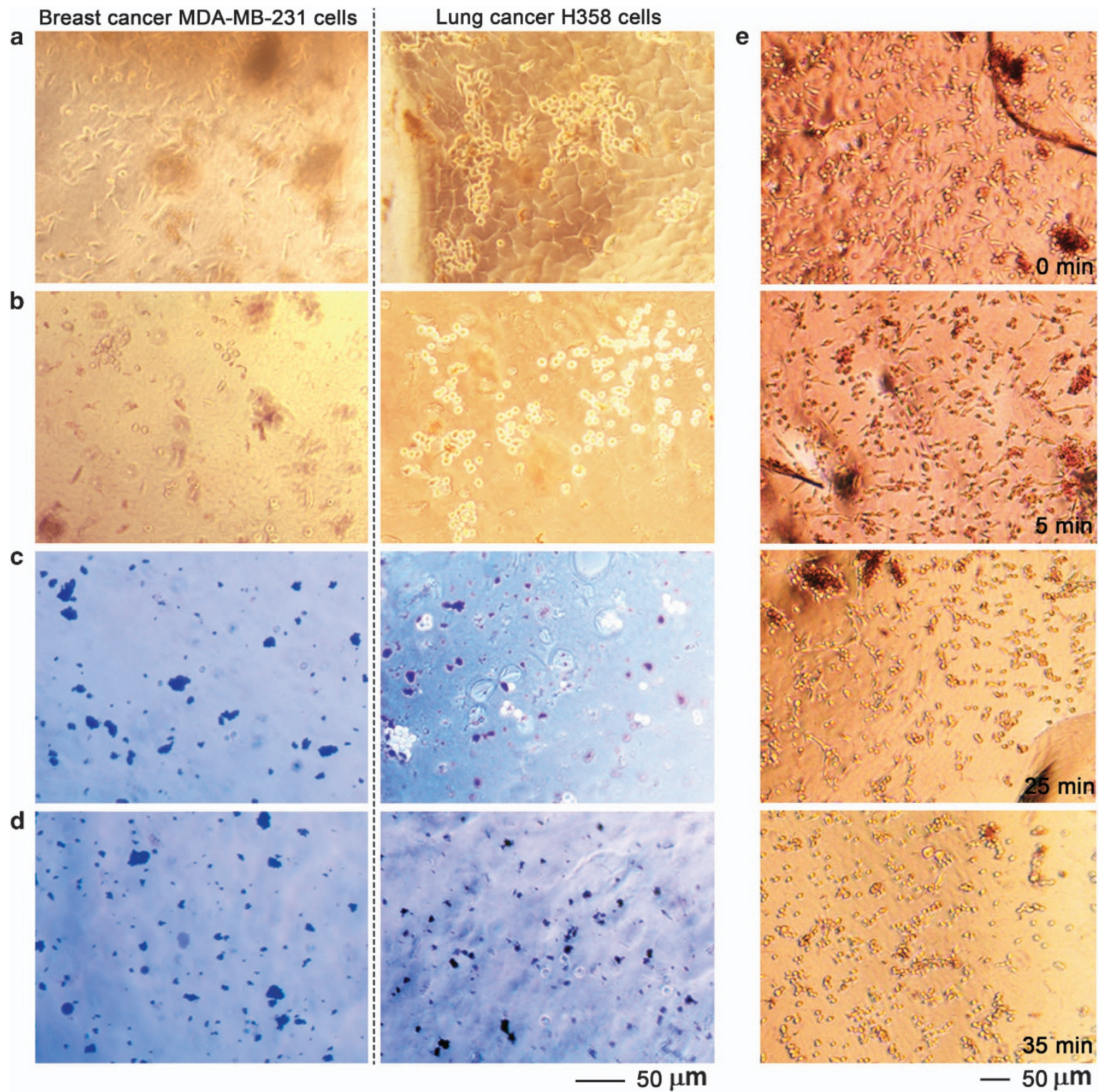

Figure 2 Cancer cells died after the temperature-responsive hydrogels expanded. Images of breast cancer MDA-MB-231 cells and lung cancer H358 cells on the surface of RGD-modified hydrogels. For the case when (a) the hydrogel was fully contracted by incubating it at $37^{\circ} \mathrm{C}$ for $48 \mathrm{~h}$ and (b) after the hydrogel was subsequently fully expanded by incubating it at $22^{\circ} \mathrm{C}$ for $35 \mathrm{~min}$. (c) Images of the cells after they were stained with trypan blue; dark spots indicate that the cells died. (d) After washing the surface of the RGD-modified hydrogels, the solution collected from washing was imaged. Dark spots were also present. (e) Morphology of MDA-MB-231 cells attached onto the surface of the RGD-modified hydrogel when the hydrogel expanded at low temperature. Images taken at $0,5,25$, and 35 min after the temperature was reduced to $22{ }^{\circ} \mathrm{C}$.

which is an amino-rich polymer. Through copolymerization, the stability of the coating can be enhanced. ${ }^{32}$ However, polyethyleneimine is known to have high cell toxicity. ${ }^{33}$ In this study, we chose PLL instead, as it is known to have good biocompatibility. Improved adhesion of cells has been shown for surfaces of different materials coated with PLL. ${ }^{34}$ Based on this rationale, we first copolymerized dopamine and PLL onto the surface of the stimuli-responsive hydrogels and then immobilized RGD peptides onto the coating via a Michael addition or Schiff base reaction (Figure 1b).

As a first demonstration, we fabricated a macroscopic (cylindrical; $4 \mathrm{~mm}$ in diameter and $300 \mu \mathrm{m}$ in height) piece of temperatureresponsive hydrogel (poly( $N$-isopropylacrylamide) (PNIPAM)) with an LCST of approximately $32^{\circ} \mathrm{C}$ and modified its surface with a layer of RGD peptides. We verified that the RGD peptides were coated onto the hydrogel by first measuring the contact angle of water (Supplementary Figure S1). When contracted at $37^{\circ} \mathrm{C}$, the hydrogel had significantly different contact angles before and after coating; hence, it seems that the surface was modified. In addition, FTIR results showed that for the hydrogel coated with RGD peptide, a peak corresponding to the $\mathrm{COOH}$ group was observed at $1710 \mathrm{~cm}^{-1}$; the appearance of this peak indicates that the RGD was successfully coated onto the hydrogel surface (Supplementary Figure S2). Analysis of the surface using XPS showed that the amount of carbon decreased and the amount of nitrogen increased after coating (Supplementary Figure S3). These measured values are in approximate agreement with the theoretical values of surfaces coated with RGD peptides.

Subsequently, we compared the performance of the temperatureresponsive hydrogel before and after coating it with RGD peptides. 


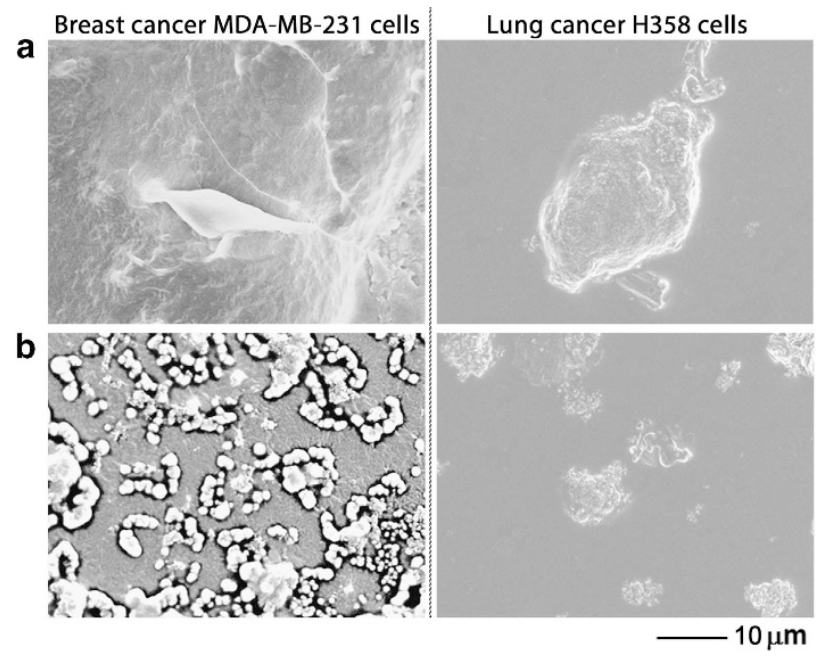

Figure 3 SEM images of the cells on the surface of the temperatureresponsive hydrogel. (a) Cells attached on the surface of an RGD-modified hydrogel that was fully contracted. (b) After the RGD-modified hydrogels expanded fully, small debris was observed on the surface of the hydrogel. The presence of the debris indicates that the cancer cells ruptured.

The ability of the hydrogel to rupture the cancer cells depends on the amount and the rate of expansion. After coating, we found that the diameters of the hydrogel when expanded and contracted were similar to that of the uncoated hydrogel (Figure 1c). The weight of the hydrogel over its dry weight (that is, the swelling ratio) measured at different temperatures and the LCST were also similar (Figure 1d). In addition, the rate of swelling (that is, the recovery ratio) was similar for the coated and uncoated hydrogels (Figure 1e).

\section{Rupturing cancer cells}

After fabricating the temperature-responsive hydrogel coated with RGD peptides, we contracted it by incubation at $37^{\circ} \mathrm{C}$. We then seeded either triple-negative breast cancer cells (MDA-MB-231) or non-small cell carcinoma lung cancer cells (H358) onto the hydrogel at $37^{\circ} \mathrm{C}$. After $48 \mathrm{~h}$, we observed that they attached onto the surface of the hydrogels coated with RGD peptides (Figure 2a) but did not attach onto the hydrogels that were not coated with RGD peptides (Supplementary Figure S4). Subsequently, we expanded the temperature-responsive hydrogel by cooling it down to $22^{\circ} \mathrm{C}$ (Figure 2 and Supplementary Figure S5). For the MDA-MB-231 cells, we observed a change in morphology of the cells when the hydrogel expanded. Initially, the cells had the characteristic elongated shape, but when the hydrogel expanded, the cells appeared rounded (Figures $2 \mathrm{~b}$ and e).

To determine whether the cells attached onto the hydrogel died after the hydrogel expanded, we stained the cells with trypan blue and washed the surface of the hydrogel three times after staining (see Supplementary Information, Sections 5 and 6, and Supplementary Figures S6-S8, in which we verified that trypan blue stained only dead cells and not live cells). When observed under a microscope, dark blue spots were clearly visible on the surface of the hydrogel-this result indicates that cells died after the hydrogel expanded (Figure 2c). We also collected the solution used to wash the surface of the hydrogel and poured it into a 24 -well plate tissue culture polystyrene dish. Similarly, we observed many dark spots in the well under the microscope; these spots represent the debris of the dead cells that was washed away from the surface of the hydrogels (Figure 2d). On the other hand, cells plated on a dish (that is, not on the surface of the coated temperature-

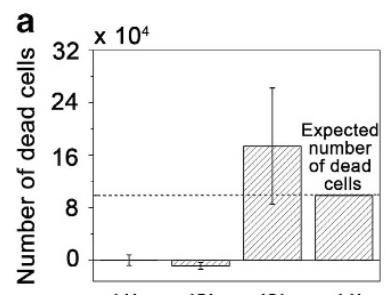

(1) (2) (3) (4)

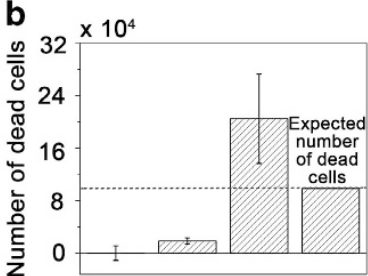

(1) (2) (3) (4)

Figure 4 Quantifying the number of dead cells via the MTT assay. The plots show the number of dead cells for (a) MDA-MB-231 cells and (b) H358 cells. (1) Cells attached on 24-well plates without any hydrogel. Cells attached on temperature-responsive hydrogels that were (2) fully contracted and (3) fully expanded. (4) The expected number of dead cells in the well calculated based on the product of the expected number of live cells and the fractional area of the hydrogel over the bottom area of the well.

responsive hydrogel) did not die when the temperature was decreased to $22^{\circ} \mathrm{C}$ for $35 \mathrm{~min}$ (Supplementary Information, Section 7, and Supplementary Figure S9).

The conditions of the cells can be observed more clearly using SEM. We analyzed two types of samples: the surface of the fully contracted hydrogel at $37^{\circ} \mathrm{C}$ and the surface of the hydrogel after it fully expanded at room temperature. These samples were freeze-dried before analyzing them by SEM. For the fully contracted hydrogel, the images showed that the cells attached on the surface of the hydrogel had morphologies that are typical of the cells (that is, elongated for MDA-MB-231 and rounded for H358; Figure 3a and Supplementary Figure S10). For the fully expanded hydrogel, the images showed debris of materials smaller than the typical size of the cells. These images showed that the cells were ruptured and had broken down into many smaller pieces (Figure $3 \mathrm{~b}$ and Supplementary Figure S10).

To quantify the number of cells that died after the expansion of the hydrogel, we first determined the number of live cells by using the MTT assay. We conducted the MTT assay for three types of experiments: when there was (i) no hydrogel and when the hydrogel was (ii) fully contracted or (iii) fully expanded. The reference number of live cells was based on experiment (i). Hence, the number of dead cells was calculated by taking the difference between the reference (i) and the number of live cells in experiment (ii) or (iii). The results showed that when the hydrogel was fully contracted, there were almost no dead cells. When the hydrogel was fully expanded, a significant number of cells were dead for both types of cells investigated (Figure 4). As a comparison, we can calculate the expected number of dead cells by taking into account the relatively smaller area occupied by the hydrogel in the well. Specifically, if the hydrogel can kill all the cells in the area that it occupies, then the expected number of dead cells is the product of the number of live cells in the well and the fraction of the area of the fully contracted hydrogel in the well. Our results showed that more cells were killed than expected (Figure 4). One explanation is that the hydrogel might have come into contact with more cells during expansion.

\section{Measuring the physical force}

The results of these experiments indicate that the force provided by the expanding temperature-responsive hydrogel was sufficient for rupturing the cancer cells. However, the fundamental mechanism of how the PNIPAM hydrogel expands when the temperature is lowered is not completely understood at the molecular level. ${ }^{35,36}$ One explanation is based on the hydrophobic groups (that is, the isopropyl 
a

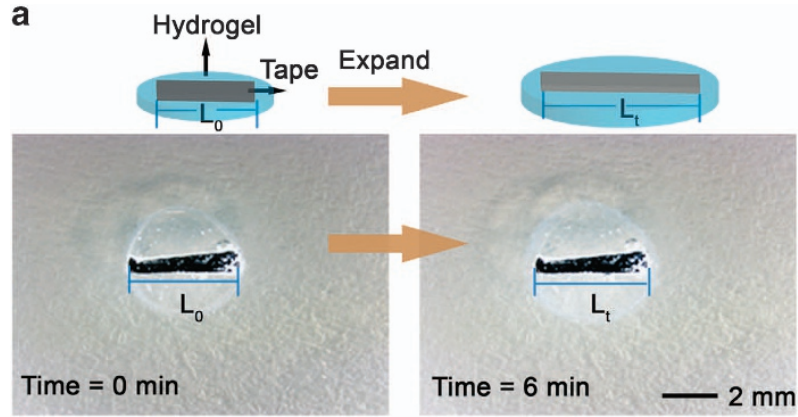

b

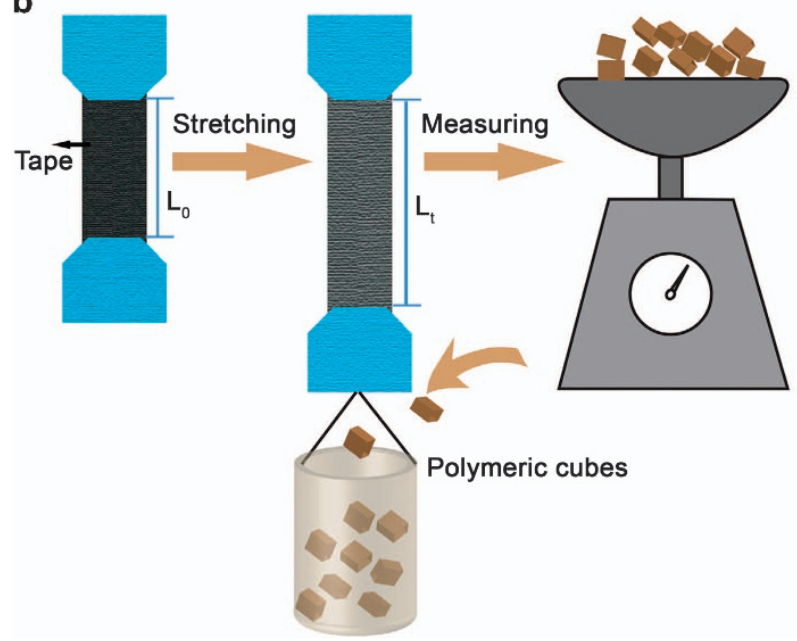

Figure 5 Measuring the lateral force of the surface of the expanding temperature-responsive hydrogel. (a) Five layers of double-sided tape were adhered onto the surface of the hydrogel (image on the left). The hydrogel was allowed to expand and stretch the tape for 6 min (image on the right). (b) Scheme illustrating the method for measuring the force required to stretch the tape to the same length as the hydrogel.

groups and the polymeric backbone) and the hydrophilic groups (that is, the amide groups) of the PNIPAM hydrogel. At low temperature, the polymeric chains adopt an extended conformation stabilized by hydrogen bonding between the hydrophilic groups of the polymer and the water molecules. These water molecules, however, need to arrange themselves in an ordered manner around the polar and nonpolar regions of the polymeric chains, thus resulting in a decrease in entropy. ${ }^{37}$ At high temperature, the interaction between the polymer and the water molecules reduced. ${ }^{38,39}$ In this case, entropy dominates: water is expelled out of the hydrogel, and the polymeric chains adopt a collapsed globule-like conformation.

Since the fundamental mechanism is not completely understood, we performed an experiment to determine the magnitude of the force produced by the expansion of the temperature-responsive hydrogel. We first adhered multiple layers of double-sided tape onto the surface of the hydrogel and then allowed the hydrogel to expand for $6 \mathrm{~min}$ (Figure 5a). For five layers of tape, the hydrogel was able to stretch it for $0.25 \mathrm{~mm}$ without bending under the stress of the tape. Subsequently, we determined the amount of load required to elongate the five layers of tape to the same length (Figure 5b). Briefly, we attached a container to the bottom of the tape and filled the container with small loads (that is, polymeric cubes) until the tape elongated to the same length (that is, $0.25 \mathrm{~mm}$ ). By measuring the weight of the total load $(\sim 1.5 \mathrm{~N})$ and taking into account the small adhesive area of a cell, we estimated that a force on the order of $\sim 80 \mu \mathrm{N}$ can act on a single cell. This force is much larger than that typically needed to rupture a cell. ${ }^{40-42}$ In addition, a stimuli-responsive hydrogel exerts the largest force when it starts expanding initially (and does not exert any force after it fully expanded); hence, we expect the force to be larger for an expansion less than $0.25 \mathrm{~mm}$ (for example, for the distance required to rupture the cell membrane).

\section{Rupturing cells using microscopic particles}

In addition to using the macroscopic pieces of hydrogels, we demonstrated that microscopic (diameter $\sim 15 \mu \mathrm{m}$ ) temperatureresponsive gel particles can also rupture cancer cells (see Supplementary Figures S11-S12 for SEM images and the size distributions of the particles). These gel particles were similarly coated with PLL and PDA and then with RGD peptides. For rupturing the cancer cells, we first added them into a 24-well plate and allowed the cells to attach onto the bottom surface of the dish at $37^{\circ} \mathrm{C}$ for $24 \mathrm{~h}$ (Figure 6a). We then added the microscopic gel particles into the wells. After another $24 \mathrm{~h}$, we allowed the gel particles to expand at a low temperature of $22^{\circ} \mathrm{C}$ for $35 \mathrm{~min}$ (Figure 6b). Subsequently, the cells were stained with trypan blue. Dark blue spots were present after the gel particles expanded (Figures $6 \mathrm{c}$ and $\mathrm{d}$ ); hence, the cells died due to the expansion of the particles. To show that the microscopic particles themselves did not cause cell death (that is, without expansion), we fabricated another type of gel particle that did not change its size with a change in temperature (Supplementary Figures S11-S12). When these gel particles were used, no dark spots were present (Figures 6e and f).

\section{CONCLUSIONS}

We showed that the physical force derived from the chemical transformation and the subsequent expansion of a temperatureresponsive hydrogel is strong enough to rupture cancer cells. To adhere the cells onto the hydrogels, we developed a method to deposit RGD peptides (that is, peptides that are commonly used for adhering cells onto a substrate) onto the surface of the hydrogels via copolymerizing the biocompatible PDA and PLL macromolecules. Since the cancer cells died after expansion, it seems that the adhesion provided by the RGD molecules is firm enough for rupturing the cells. Another advantage of using RGD peptides is that previous studies have used these RGD peptides for targeting cancer cells or tumor sites. ${ }^{43,44}$ The amount and the rate of expansion of the temperature-responsive hydrogels after coating remained unchanged. Experimentally, we measured that the force of the expanding hydrogel was greater than the typical force needed to rupture cells. The lysis tensions of cell membranes of different types of cells typically lie within a narrow range (for example, on the order of $1 \mathrm{mN} \mathrm{m}^{-1}$ to $\left.10 \mathrm{mN} \mathrm{m}^{-1}\right) .{ }^{41,42,45,46}$ Therefore, this approach may potentially be general for rupturing a wide range of cells.

This approach has several other advantages. Both macroscopic $(\sim \mathrm{mm})$ and microscopic $(\sim 15 \mu \mathrm{m})$ hydrogels were demonstrated to work; hence, particles of other sizes that are within this range may potentially be used with similar effects. As such, this approach has many of the advantages of using particles for treating cancer (for example, minimally invasive, easily administered and applicable to different parts of the body). For example, microscopic hydrogels injected intravenously into mice were found to have long circulation times and have been proposed to be used for therapeutic purposes. ${ }^{4}$ On the other hand, it may be challenging for smaller gel particles (for example, those on the order of a few hundred nanometers) to be effective due to other complications (for example, the fluidity of 


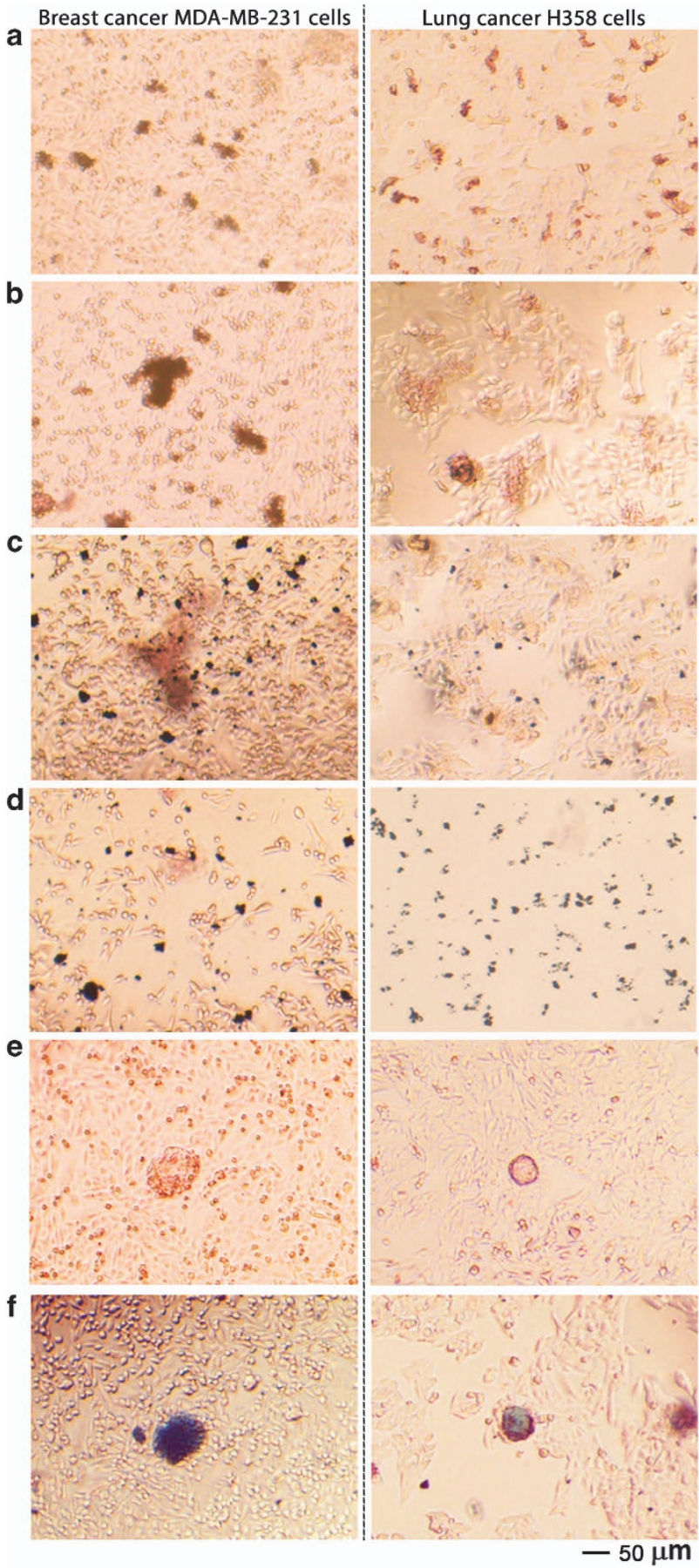

Figure 6 Using microscopic temperature-responsive gel particles for rupturing cancer cells. (a) Images of the cells and the RGD-modified microscopic temperature-responsive gel particles after incubating them at $37^{\circ} \mathrm{C}$ for $24 \mathrm{~h}$ and (b) after subsequently expanding the gel particles at $22^{\circ} \mathrm{C}$ for $35 \mathrm{~min}$. Images of the cells and the gel particles located (c) in the center and (d) by the sides of the 24-well plates after expanding the gel particles and staining the remains of the cells with trypan blue. (e) Images of the cells and the gel particles that were not responsive to temperature after incubating them at $22^{\circ} \mathrm{C}$ for $35 \mathrm{~min}$. (f) Images of the cells and the gel particles that were not responsive to temperature after staining with trypan blue.

the cell membrane and endocytosis). Another advantage of this approach is that stimuli-responsive hydrogels are generally regarded as 'smart' drug carriers in the field of drug delivery that can target a specific site. ${ }^{47,48}$ For example, the tumor microenvironment is known to be acidic and has a slightly elevated temperature. ${ }^{49,50}$ A temperature-responsive and/or a $\mathrm{pH}$-responsive hydrogel can target the tumor site specifically by expanding only at the localized site, thereby reducing damage to healthy cells.

After establishing that the physical force derived from the expanding hydrogel is sufficient for rupturing cancer cells, more work will be needed to further develop the technology. For example, specific targeting of cancer cells can potentially be achieved by replacing the RGD coating with molecules that bind specifically to cancer cells. ${ }^{51-53}$ For this approach to be compatible with existing methods for treating cancer (for example, therapeutic hypothermia, hyperthermia therapy, or the use of an electric field; see Supplementary Information, Section 1), different types of stimuli-responsive hydrogels may need to be fabricated (for example, hydrogels that expand at high temperature or respond to an electric field) ${ }^{54,55}$ Fully biocompatible materials (for example, biocompatible temperature-responsive hydrogel) will also be needed. ${ }^{56}$ There will be many challenges ahead before this technology can be implemented in practical circumstances; examples include fabricating the coated stimuli-responsive hydrogel with all the required material properties (for example, biocompatibility of the hydrogel and coating, specificity of the coating for targeting cancer cells, and sufficient response) so that they are effective in a complex in vivo environment.

Although more work needs to be done before we can fully assess the effectiveness of this approach, it has characteristics that are promising compared to other methods (that is, those that also use particles). Importantly, the approach involves a fundamentally different mechanism-a physical force. Based on our analyses, this approach can potentially be general for a wide range of cells. In addition, it is conceptually simple and is technically easy to implement (for example, preparation of the hydrogel is simple). In comparison, other chemical (for example, chemotherapy) and biological (for example, immunotherapy) methods may require a combination of complex organic synthesis of (for example, drug) molecules, extensive testing of the effectiveness of each of the synthesized molecules, and fundamental knowledge of the underlying biomolecular mechanism for killing specific types of cancer cells. Because of these advantageous characteristics, it will be interesting to develop the technology further and fully compare these features with other methods.

\section{CONFLICT OF INTEREST}

The authors declare no conflict of interest.

\section{ACKNOWLEDGEMENTS}

This work was financially supported by the Ministry of Education, Singapore, under grant R-279-000-398-133.

\section{PUBLISHER'S NOTE}

Springer Nature remains neutral with regard to jurisdictional claims in published maps and institutional affiliations.

1 World Health Organization. Cancer (2017) http://www.who.int/mediacentre/factsheets/ fs297/en/.

2 Feng, S. S. Nanoparticles of biodegradable polymers for new-concept chemotherapy. Expert Rev. Med. Devices 1, 115-125 (2004).

3 De Souza, R., Zahedi, P., Allen, C. J. \& Piquette-Miller, M. Polymeric drug delivery systems for localized cancer chemotherapy. Drug Deliv. 17, 365-375 (2010).

4 Merkel, T. J., Jones, S. W., Herlihy, K. P., Kersey, F. R., Shields, A. R., Napier, M., Luft, J. C., Wu, H. L., Zamboni, W. C., Wang, A. Z., Bear, J. E. \& DeSimone, J. M. Using mechanobiological mimicry of red blood cells to extend circulation times of hydrogel microparticles. Proc. Natl Acad. Sci. USA 108, 586-591 (2011). 
5 Therasse, P., Arbuck, S. G., Eisenhauer, E. A., Wanders, J., Kaplan, R. S., Rubinstein, L., Verweij, J., Van Glabbeke, M., van Oosterom, A. T., Christian, M. C. \& Gwyther, S. G. New guidelines to evaluate the response to treatment in solid tumors. J. Natl. Cancer Inst. 92, 205-216 (2000).

6 Kratz, F. in Drug Delivery in Oncology: from Basic Research to Cancer Therapy (eds Kratz, F., Senter, P. \& Steinhagen, H.) (John Wiley \& Sons, Hoboken, NJ, USA, 2011).

7 Dolmans, D. E., Fukumura, D. \& Jain, R. K. Photodynamic therapy for cancer. Nat. Rev. Cancer 3, 380-387 (2003).

8 Huang, X., El-Sayed, I. H., Qian, W. \& El-Sayed, M. A. Cancer cell imaging and photothermal therapy in the near-infrared region by using gold nanorods. J. Am. Chem. Soc. 128, 2115-2120 (2006).

9 Yang, K., Zhang, S., Zhang, G., Sun, X., Lee, S. T. \& Liu, Z. Graphene in mice: ultrahigh in vivo tumor uptake and efficient photothermal therapy. Nano Lett. 10, 3318-3323 (2010).

10 Qiu, Y. \& Park, K. Environment-sensitive hydrogels for drug delivery. Adv. Drug Del. Rev. 53, 321-339 (2001)

11 Bajpai, A., Shukla, S. K., Bhanu, S. \& Kankane, S. Responsive polymers in controlled drug delivery. Prog. Polym. Sci. 33, 1088-1118 (2008).

12 Kumar, C. S. \& Mohammad, F. Magnetic nanomaterials for hyperthermia-based therapy and controlled drug delivery. Adv. Drug Deliv. Rev. 63, 789-808 (2011).

13 Medeiros, S., Santos, A., Fessi, H. \& Elaissari, A. Stimuli-responsive magnetic particles for biomedical applications. Int. J. Pharm. 403, 139-161 (2011).

14 Fleige, E., Quadir, M. A. \& Haag, R. Stimuli-responsive polymeric nanocarriers for the controlled transport of active compounds: concepts and applications. Adv. Drug Deliv. Rev. 64, 866-884 (2012).

$15 \mathrm{Kim}$, D. H. \& Wirtz, D. Focal adhesion size uniquely predicts cell migration. FASEB J. 27, 1351-1361 (2013).

16 Kato, M. \& Mrksich, M. Using model substrates to study the dependence of focal adhesion formation on the affinity of integrin-ligand complexes. Biochemistry 43 2699-2707 (2004)

17 Kandere-Grzybowska, K., Soh, S., Mahmud, G., Komarova, Y., Pilans, D. \& Grzybowski, B. A. Short-term molecular polarization of cells on symmetric and asymmetric micropatterns. Soft Matter 6, 3257-3268 (2010).

18 Acharya, A. P., Dolgova, N. V., Moore, N. M., Xia, C. Q., Clare-Salzler, M. J., Becker, M. L., Gallant, N. D. \& Keselowsky, B. G. The modulation of dendritic cell integrin binding and activation by RGD-peptide density gradient substrates. Biomaterials 31 , 7444-7454 (2010).

19 Alvarez-Barreto, J. F. \& Sikavitsas, V. I. Improved mesenchymal stem cell seeding on RGD-modified poly(L-lactic acid) scaffolds using flow perfusion. Macromol. Biosci. 7, 579-588 (2007)

20 Kolodziej, C. M., Kim, S. H., Broyer, R. M., Saxer, S. S., Decker, C. G. \& Maynard, H. D. Combination of integrin-binding peptide and growth factor promotes cell adhesion on electron-beam-fabricated patterns. J. Am. Chem. Soc. 134, 247-255 (2012).

21 Larsen, C. C., Kligman, F., Kottke-Marchant, K. \& Marchant, R. E. The effect of RGD fluorosurfactant polymer modification of ePTFE on endothelial cell adhesion, growth, and function. Biomaterials 27, 4846-4855 (2006).

22 Chan, B. P., Reichert, W. M. \& Truskey, G. A. Effect of streptavidin RGD mutant on the adhesion of endothelial cells. Biotechnol. Progr. 20, 566-575 (2004).

23 Marchi-Artzner, V., Lorz, B., Hellerer, U., Kantlehner, M., Kessler, H. \& Sackmann, E. Selective adhesion of endothelial cells to artificial membranes with a synthetic RGDlipopeptide. Chem-Eur. J. 7, 1095-1101 (2001).

24 Bodin, A., Ahrenstedt, L., Fink, H., Brumer, H., Risberg, B. \& Gatenholm, P. Modification of nanocellulose with a xyloglucan-RGD conjugate enhances adhesion and proliferation of endothelial cells: implications for tissue engineering. Biomacromolecules 8, 3697-3704 (2007).

25 Roberts, C., Chen, C. S., Mrksich, M., Martichonok, V., Ingber, D. E. \& Whitesides, G. M. Using mixed self-assembled monolayers presenting RGD and (EG) $30 \mathrm{H}$ groups to characterize long-term attachment of bovine capillary endothelial cells to surfaces. J. Am. Chem. Soc. 120, 6548-6555 (1998).

26 Tugulu, S., Silacci, P., Stergiopulos, N. \& Klok, H. A. RGD-functionalized polymer brushes as substrates for the integrin specific adhesion of human umbilical vein endothelial cells. Biomaterials 28, 2536-2546 (2007)

27 Su, X., Zong, Y., Richter, R. \& Knoll, W. Enzyme immobilization on poly (ethylene-coacrylic acid) films studied by quartz crystal microbalance with dissipation monitoring. J. Colloid Interface Sci. 287, 35-42 (2005).

28 Wang, Z. X., Lau, C. H., Zhang, N. Q., Bai, Y. P. \& Shao, L. Mussel-inspired tailoring of membrane wettability for harsh water treatment. J. Mater. Chem. A 3, 2650-2657 (2015).

29 Zhang, Y., Thingholm, B., Goldie, K. N., Ogaki, R. \& Städler, B Assembly of poly (dopamine) films mixed with a nonionic polymer. Langmuir 28, 17585-17592 (2012).

30 Liu, Y., Chang, C. P. \& Sun, T. Dopamine-assisted deposition of dextran for nonfouling applications. Langmuir 30, 3118-3126 (2014).

31 Zhou, R., Ren, P. F., Yang, H. C. \& Xu, Z. K. Fabrication of antifouling membrane surface by poly (sulfobetaine methacrylate)/polydopamine co-deposition. J. Membr. Sci. 466 18-25 (2014)

32 Yang, H. C., Chen, Y. F., Ye, C., Jin, Y. N., Li, H. \& Xu, Z. K. Polymer membrane with a mineral coating for enhanced curling resistance and surface wettability. Chem. Commun. 51, 12779-12782 (2015).

33 Beyerle, A., Irmler, M., Beckers, J., Kissel, T. \& Stoeger, T. Toxicity pathway focused gene expression profiling of PEI-based polymers for pulmonary applications. Mol. Pharm. 7, 727-737 (2010).
34 Huang, W., Gibson, S. J., Facer, P., Gu, J. \& Polak, J. M. Improved section adhesion for immunocytochemistry using high molecular weight polymers of L-lysine as a slide coating. Histochem. Cell Biol. 77, 275-279 (1983).

35 IImain, F., Tanaka, T. \& Kokufuta, E. Volume transition in a gel driven by hydrogen bonding. Nature 349, 400-401 (1991).

36 Füllbrandt, M., Ermilova, E., Asadujjaman, A., Hölzel, R., Bier, F. F., von Klitzing, R. \& Schönhals, A Dynamics of linear poly ( $N$-isopropylacrylamide) in water around the phase transition investigated by dielectric relaxation spectroscopy. J. Phys. Chem. B 118, 3750-3759 (2014).

37 Schild, H. G. Poly ( $N$-isopropylacrylamide): experiment, theory and application. Prog. Polym. Sci. 17, 163-249 (1992).

38 Katsumoto, Y., Tanaka, T., Sato, H. \& Ozaki, Y. Conformational change of poly ( $N$ isopropylacrylamide) during the coil-globule transition investigated by attenuated total reflection/infrared spectroscopy and density functional theory calculation. J. Phys. Chem. A 106, 3429-3435 (2002).

39 Ahmed, Z., Gooding, E. A., Pimenov, K. V., Wang, L. \& Asher, S. A. UV resonance raman determination of molecular mechanism of poly ( $\mathrm{N}$-isopropylacrylamide) volume phase transition. J. Phys. Chem. B 113, 4248-4256 (2009).

40 Zhang, Z., Al-Rubeai, M. \& Thomas, C. Mechanical properties of hybridoma cells in batch culture. Biotechnol. Lett. 14, 11-16 (1992).

41 Morris, C. \& Homann, U. Cell surface area regulation and membrane tension. J. Membrane Biol. 179, 79-102 (2001).

42 Boal, D. H. in Mechanics of the Cell (ed. Boal, D. H.) (Cambridge University, UK, 2002)

43 Danhier, F., Le Breton, A. \& Préat, V. RGD-based strategies to target alpha(v) beta(3) integrin in cancer therapy and diagnosis. Mol. Pharm. 9, 2961-2973 (2012).

44 Danhier, F., Vroman, B., Lecouturier, N., Crokart, N., Pourcelle, V., Freichels, H., Jérôme, C., Marchand-Brynaert, J., Feron, O. \& Préat, V. Targeting of tumor endothelium by RGD-grafted PLGA-nanoparticles loaded with paclitaxel. J. Control. Release 140, 166-173 (2009).

45 Tan, S. C. W., Yang, T., Gong, Y. \& Liao, K. Rupture of plasma membrane under tension. J. Biomech. 44, 1361-1366 (2011).

46 Gözen, I., Dommersnes, P., Czolkos, I., Jesorka, A., Lobovkina, T. \& Orwar, O. Fractal avalanche ruptures in biological membranes. Nat. Mater. 9, 908-912 (2010).

47 De las Heras Alarcón, C., Pennadam, S. \& Alexander, C. Stimuli responsive polymers for biomedical applications. Chem. Soc. Rev. 34, 276-285 (2005).

48 Stuart, M. A. C., Huck, W. T., Genzer, J., Müller, M., Ober, C., Stamm, M., Sukhorukov, G. B., Szleifer, I., Tsukruk, V. V., Urban, M., Winnik, F., Zauscher, S., Luzinov, I. \& Minko, S. Emerging applications of stimuli-responsive polymer materials. Nat. Mater. 9, 101-113 (2010).

49 Gillies, R. J., Schornack, P. A., Secomb, T. W. \& Raghunand, N. Causes and effects of heterogeneous perfusion in tumors. Neoplasia 1, 197-207 (1999).

50 Zhang, L., Guo, R., Yang, M., Jiang, X. \& Liu, B. Thermo and pH dual-responsive nanoparticles for anti-cancer drug delivery. Adv. Mater. 19, 2988-2992 (2007).

51 Cortez, C., Tomaskovic-Crook, E., Johnston, A. P., Scott, A. M., Nice, E. C., Heath, J. K. $\&$ Caruso, F. Influence of size, surface, cell line, and kinetic properties on the specific binding of A33 antigen-targeted multilayered particles and capsules to colorectal cancer cells. ACS Nano 1, 93-102 (2007).

52 Hou, S., Zhao, H., Zhao, L., Shen, Q., Wei, K. S., Suh, D. Y., Nakao, A., Garcia, M., Song, M., Lee, T., Xiong, B., Luo, S. C., Tseng, H. R. \& Yu, H. H. Capture and stimulated release of circulating tumor cells on polymer-grafted silicon nanostructures. Adv. Mater. 25, 1547-1551 (2013).

53 Dai, Q., Walkey, C. \& Chan, W. C. Polyethylene glycol backfilling mitigates the negative impact of the protein corona on nanoparticle cell targeting. Angew. Chem. Int. Ed. 53, 5093-5096 (2014).

54 Spizzirri, U. G., lemma, F., Puoci, F., Xue, F., Gao, W., Cirillo, G., Curcio, M., Parisi, O. I. \& Picci, N. Synthesis of hydrophilic microspheres with LCST close to body temperature for controlled dual-sensitive drug release. Polym. Adv. Technol. 22, 1705-1712 (2011).

55 Sarmad, S., Yenici, G., Gürkan, K., Keçeli, G. \& Gürdağ, G. Electric field responsive chitosan-poly ( $N, N$-dimethyl acrylamide) semi-IPN gel films and their dielectric, thermal and swelling characterization. Smart Mater. Struct. 22, 055010 (2013).

56 Nagahama, K., Hashizume, M., Yamamoto, H., Ouchi, T. \& Ohya, Y. Hydrophobically modified biodegradable poly(ethylene glycol) copolymers that form temperatureresponsive nanogels. Langmuir 25, 9734-9740 (2009).

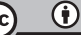

This work is licensed under a Creative Commons Attribution 4.0 International License. The images or other third party material in this article are included in the article's Creative Commons license, unless indicated otherwise in the credit line; if the material is not included under the Creative Commons license, users will need to obtain permission from the license holder to reproduce the material. To view a copy of this license, visit http:// creativecommons.org/licenses/by/4.0/

(C) The Author(s) 2018 